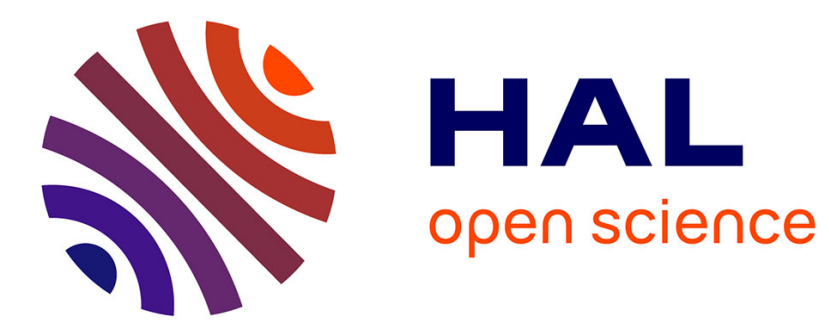

\title{
LASER TECHNIQUES FOR SPECTROSCOPY OF CORE-EXCITED ATOMIC LEVELS
}

\author{
S. Harris, J. Young, R. Falcone, J. Rothenberg, J. Willison
}

\section{To cite this version:}

S. Harris, J. Young, R. Falcone, J. Rothenberg, J. Willison. LASER TECHNIQUES FOR SPECTROSCOPY OF CORE-EXCITED ATOMIC LEVELS. Journal de Physique Colloques, 1982, 43 (C2), pp.C2-243-C2-254. 10.1051/jphyscol:1982218 . jpa-00221829

\section{HAL Id: jpa-00221829 https://hal.science/jpa-00221829}

Submitted on 1 Jan 1982

HAL is a multi-disciplinary open access archive for the deposit and dissemination of scientific research documents, whether they are published or not. The documents may come from teaching and research institutions in France or abroad, or from public or private research centers.
L'archive ouverte pluridisciplinaire HAL, est destinée au dépôt et à la diffusion de documents scientifiques de niveau recherche, publiés ou non, émanant des établissements d'enseignement et de recherche français ou étrangers, des laboratoires publics ou privés. 
JOURNAL DE PHYSIQUE

Colzoque C2, supplément au n¹1, Tome 43, novembre 1982

page $\mathrm{C} 2-243$

\title{
LASER TECHNIQUES FOR SPECTROSCOPY OF CORE-EXCITED ATOMIC LEVELS
}

\author{
S.E. harris, J.F. Young, R.W. Falcone, J.E. Rothenberg and J.R. Willison \\ Edward L. Ginzton Laboratory, Stanford University, Stanford, Califomia 94305 \\ U.S.A.
}

\begin{abstract}
Résumé.- Nous exposons trois techniques permettant l'utilisation de lasers accordables pour la spectroscopie à haute résolution et pour la spectroscopie picoseconde d'états atomiques excités en couches internes. Ce sont la spectroscopie d'absorption anti-Stokes, 1'émission 1aser induite à partir d'états métastables et $\mathbf{l}^{\prime}$ excitation laser sélective d'états excités en couches internes.

Abstract.- We discuss three thechniques which allow the use of tunable lasers for high resolution and picosecond time scale spectroscopy of core-excited atomic levels. These are : anti-Stokes absorption spectroscopy, laser induced emission from metastable levels, and laser designation of selected core-excited leve1s.
\end{abstract}

1. Introduction.- Over the last ten years, tunable laser technology has grown at a remarkable rate. By using combinations of dye lasers, frequency doublers and triplers, Raman shifters, and optical parametric oscillators, most of the spectral region between $500 \mathrm{~cm}^{-1}$ to $100,000 \mathrm{~cm}^{-1}$ may now be accessed. In thi.s paper we will discuss several techniques which allow the use of this tunable laser technology for high resolution and picosecond time scale spectroscopy of core-excited atomic levels.

Our interest in these levels arises as a result of their relevance to the construction of extreme ultraviolet (XUV) lasers. In the alkali atoms, core-excited levels in the doublet series which have odd angular momentum and even parity, or even angular momentum and odd parity, are prohibited by LS selection rules from autoionizing into the ground ionic level. Figure 1 shows energy level diagrams for possible XUV lasers in $\mathrm{Li}$ and $\mathrm{k} .{ }^{1,2}$ In both cases, energy is first stored in a pure quartet level which lies at or near the bottom of the quartet manifold. The levels are populated by direct electron excitation or by charge transfer from the excited ion. An intense, short pulse tunable laser is then used to transfer this population to the upper level of the lasing transition. The $1 \mathrm{~s} 2 \mathrm{p}^{2} 2 \mathrm{P}$ level of $\mathrm{Li}$ decays primarily by emission at $207 \AA$, with a calculated radiative lifetime of $35 \mathrm{ps}$. The lower leve 1 of the laser transition $\mathrm{Li}\left(1 \mathrm{~s}^{2} 2 \mathrm{p} \mathrm{P}^{\circ}\right)$ may be emptied by the same laser which is used for the quartet to doublet transfer, or by a second laser tuned to a discrete leve1 near to the lowest continuum.

2. Anti-Stokes Absorption Spectroscopy.- The first of the techniques discussed here is based on spontaneous anti-Stokes scattering from atoms stored in a metastable level in an electrical discharge. 3 The result is a radiation source which is tunable, narrow band, has prescribed polarization and, of special interest, may be of picosecond time scale. As demonstrated by zych, et al., ${ }^{4}$ the maximum intensity 


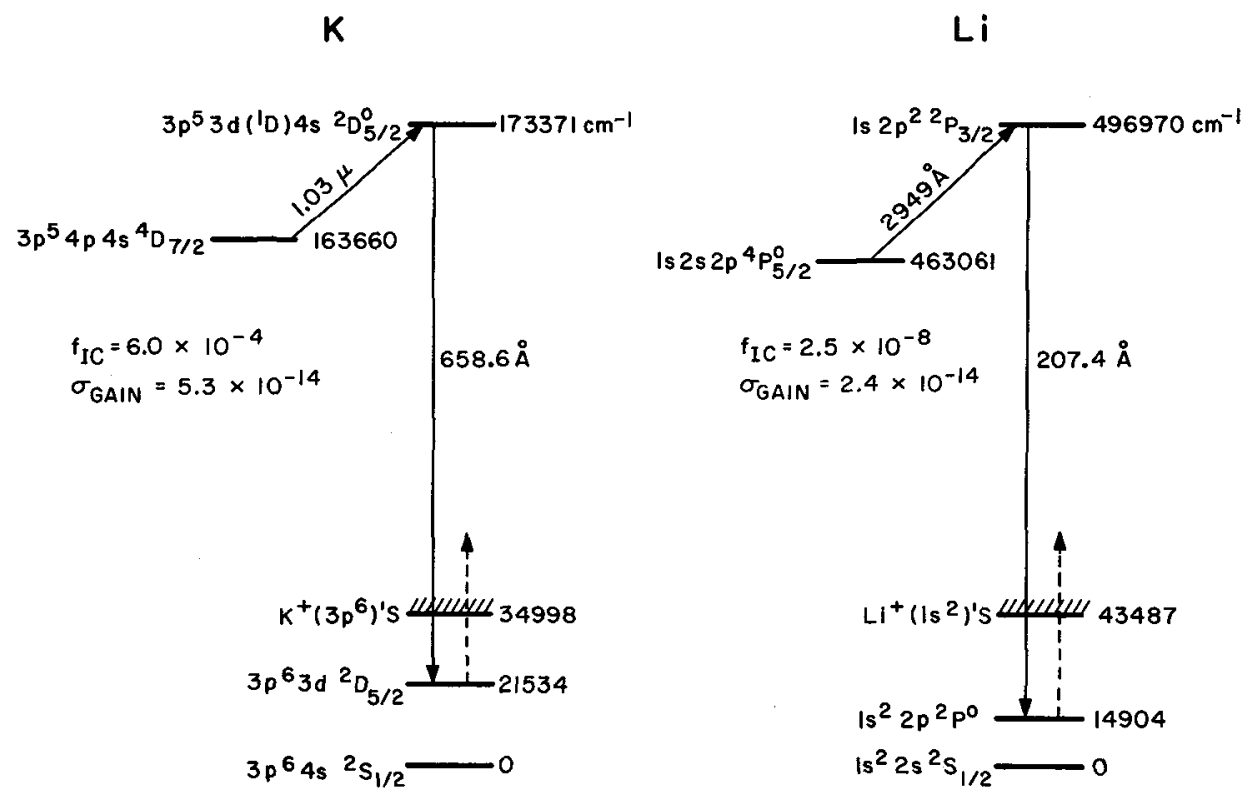

Fig. 1 : Energy level diagrams for quartet to doublet transfer in $L i$ and $K$. An incident laser is used to transfer population from a quartet storage level to a doublet (upper) laser leve1. The same laser, or a second laser, is used to deplete the lower laser level.

of this radiation source is determined by the effective temperature of the storage leve1; for example, the (1s2s) ${ }^{1} \mathrm{~S}$ level of He or $\mathrm{Li}^{+}$. Since this level does not spontaneously decay, its accumulated population and, therefore, the peak source intensity, may exceed that of a radiating level by a factor of several thousand. To reach this peak intensity the applied visible laser must cause the media to become two-photon opaque to the generated XUV radiation. In this sense the radiation source functions as a two-photon blackbody.

Figure 2 shows a schematic of apparatus for using the anti-Stokes process as an external source of radiation for high resolution absorption spectroscopy of the $3 \mathrm{p}^{6}$ shell of $\mathrm{k} .{ }^{5}$ The He $1 \mathrm{~s} 2 \mathrm{~s}^{1} \mathrm{~S}$ level at $166,277 \mathrm{~cm}^{-1}$ is used as the metastable storage level. Table 1 shows the spectral regions studied and Fig. 3 shows the results of a typical scan.

For the operating conditions of the hollow cathode glow discharge ( 2 torr $300 \mathrm{~mA}$ ), we estimate that the metastable singlet He population was about $5 \times 10^{11}$ atoms $/ \mathrm{cm}^{3}$. For photons at $6000 \AA$ the anti-Stokes scattering cross section is $4 \times 10^{-23} \mathrm{~cm}^{2}$. An incident laser pulse of $50 \mathrm{~mJ}$ produces about $2 \times 10^{8} \mathrm{xuV}$ photons in the $60 \mathrm{~cm}$ cell length. The solid angle subtended by the detector reduces the measured signal (through the aluminum filter) to about 20 photons/pulse or 200 photons/sec. This signal is about three times larger than that produced by the 


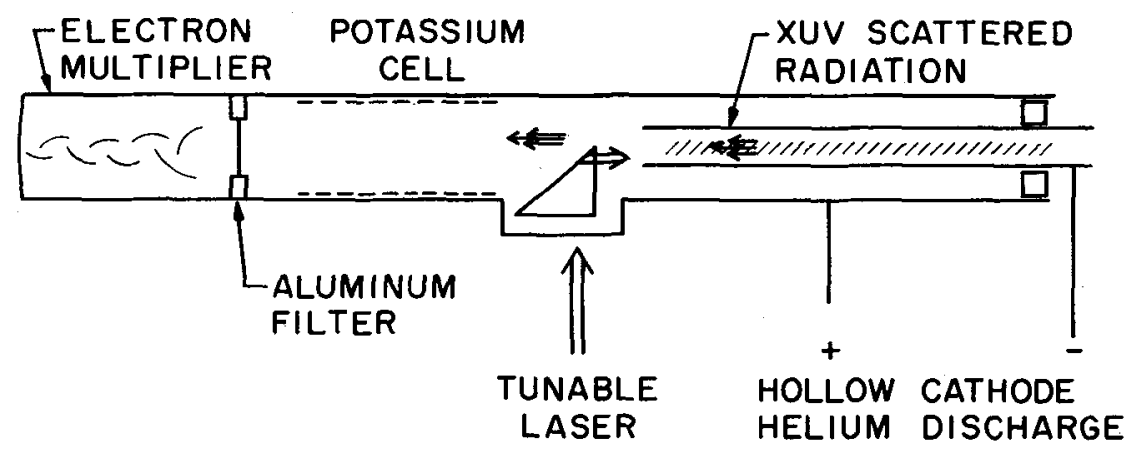

Fig. 2 : Schematic of apparatus used for absorption spectroscopy of $\mathrm{K}$.

Table 1 : Spectral regions studied.

\begin{tabular}{|c|c|c|}
\hline Laser Dye & $\begin{array}{c}\text { Range of } \\
\text { Laser Wavelength } \\
(\AA)\end{array}$ & $\begin{array}{c}\text { Range of } \\
\text { XuV Frequency } \\
\left(\mathrm{cm}^{-1}\right)\end{array}$ \\
\hline Kiton Red 620 & $5990-5740$ & $182975-183695$ \\
\hline Rhodamine 590 & $5760-5470$ & $183635-184549$ \\
\hline Coumarin 500 & $5220-4880$ & $185435-186769$ \\
\hline
\end{tabular}

background light from the plasma (Fig. 2) and, therefore, no monochromator need be used with the device. We note that the narrower features in Fig. 3 have not been previous ly observed.

In order to increase the intensity of the radiation source we have constructed a high power microwave pumped He discharge (Fig. 4) which operates in the recombination mode. At a few torr pressure and $500 \mathrm{~kW}$ of pulsed $\mathrm{X}$-band power we estimate a singlet storage density of about $10^{13}$ atoms $/ \mathrm{cm}^{3}$, with an increase in output signal (compared to the $\mathrm{cw}$ hollow cathode device) of about a factor of 1000 . Part of this increase results from better use of grazing incidence in this geometry. Unfortunately, the higher power discharge also produces much more background radiation than did the $\mathrm{cw}$ device and, at this time, it is necessary to use a monochromator as a bandpass filter in order to take spectra. 
The intensity of the microwave pumped device (about $10^{8}$ photons per second) may be sufficient to allow its use for ejected electron and fluorescence spectroscopy. In these cases, the narrow band absorption of the target species acts as a filter against unwanted background radiation.
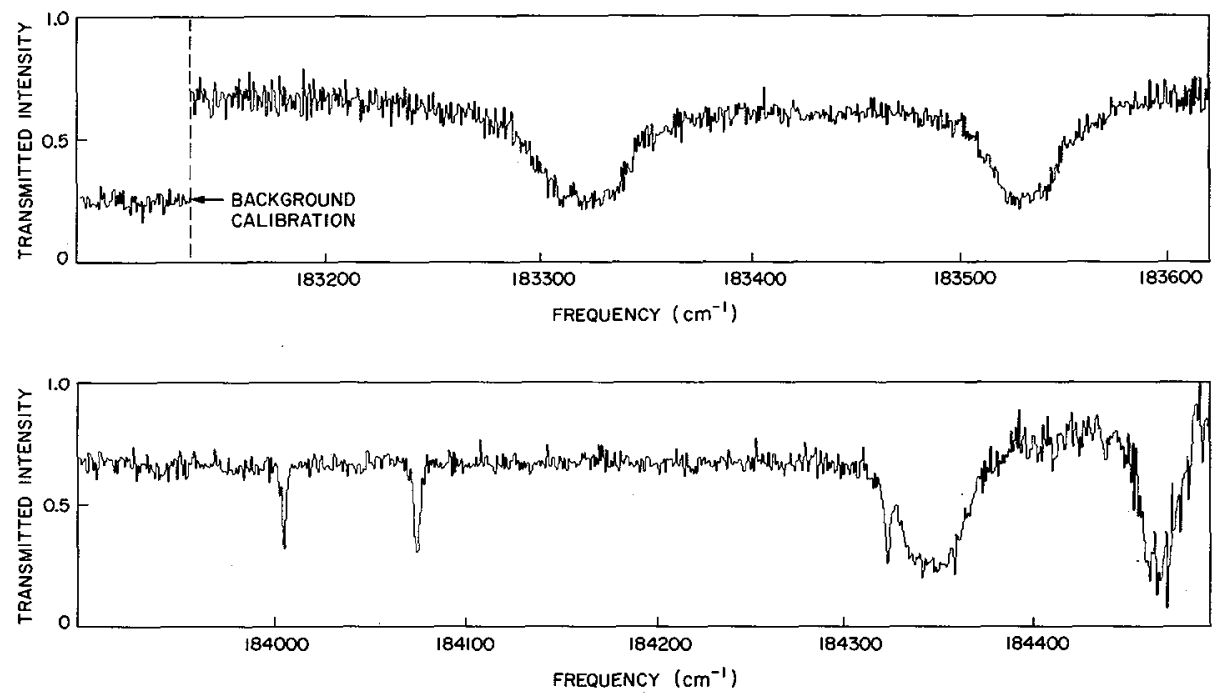

Fig. 3 : Absorption scans of $\mathrm{K}$. Vapor pressure is $10^{15}$ atoms $/ \mathrm{cm}^{3}$, and cell length is $5 \mathrm{~cm}$.

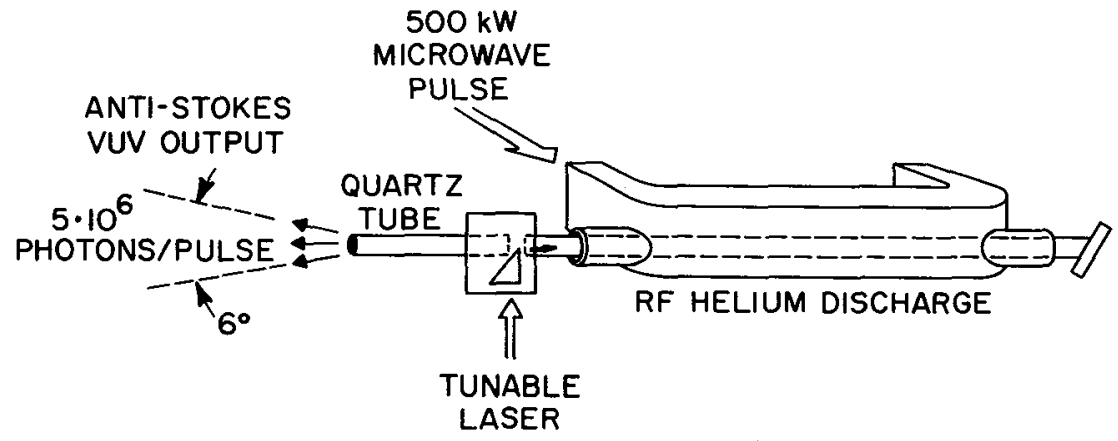

Fig. 4 : Microwave pumped anti-stokes radiation source. 
3. Emission Spectroscopy of Lithium.- We next describe an experiment in which a tunable laser is used to cause the intercombination transfer of metastable 1s2s2p ${ }^{4} \mathrm{P}_{5 / 2}$ Li atoms to the $1 s 2 \mathrm{p}^{2}{ }^{2} \mathrm{P}_{3 / 2}$ leve1, with subsequent radiation in the XUV, thereby providing the first direct tie between the quartet and doublet manifolds of neutra1 Li (Fig. 1). 6

A schematic of the apparatus is shown in Fig. 5. Metastable atoms were prepared by electron impact excitation in a microwave heated Li discharge. The ce11 consisted of a ridged X-band waveguide and was driven by a $50 \mathrm{~kW}, 9 \mathrm{GHz}$ pulsed magnetron. The incident laser beam had an energy of about $10 \mathrm{~mJ}$ and was focused to an area of about $2 \times 10^{-3} \mathrm{~cm}^{2}$ beneath the ridge. The laser-induced XUV radiation was detected by a windowless photomultiplier located behind a 1000 \&-thick aluminum filter, and a chopper whell. The aluminum filter prevented visible and near-UV radiation and ions from entering the detector. The chopper wheel, synchronized to the laser and magnetron pulses, reduced the accumulation of $\mathrm{Li}$ on the aluminum filter and significantly extended operating times.

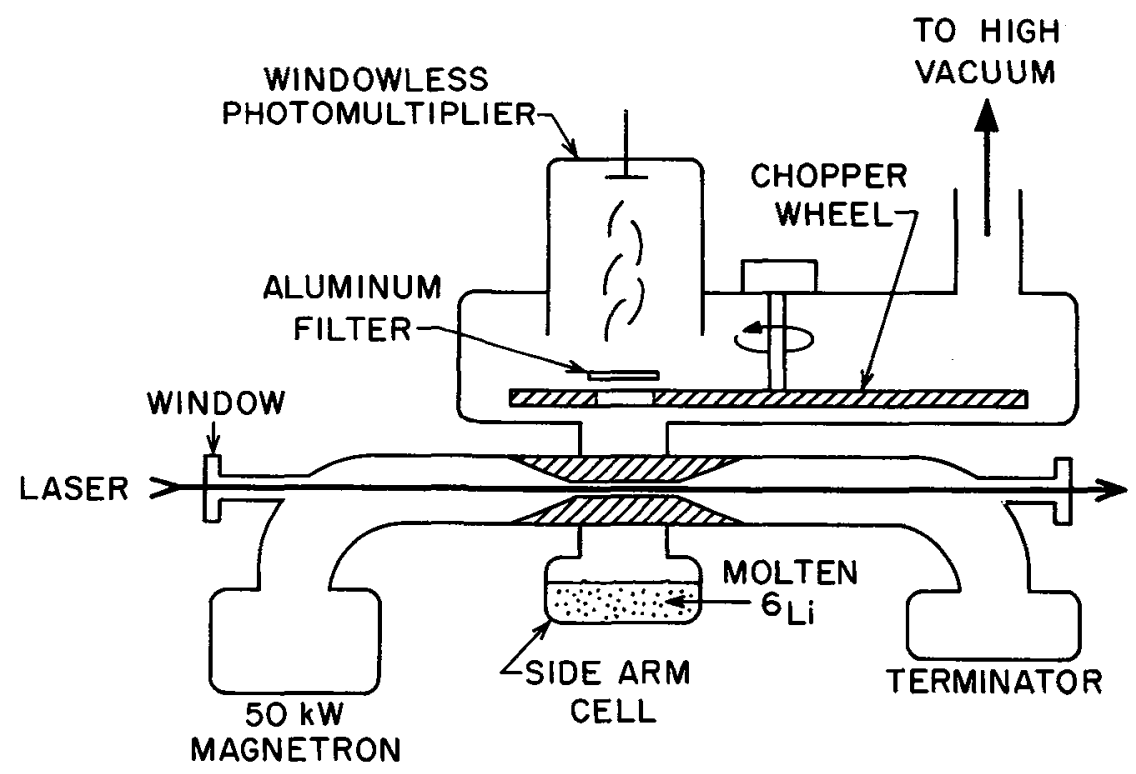

Fig. 5 : Experimental apparatus for intercombination transfer.

The signal from the electron multiplier was integrated over a 10-ns gate coincident with the laser, and then digitized and recorded by a microcomputer. The laser power was also recorded on each shot. During an experiment the laser wavelength was scanned many times through the region of interest, under computer control. The results from each scan were added to previous scans and averaged. 
The apparatus was designed to be able to detect transitions with very small oscillator strengths. For example, for the $1 s 2 s 2 p{ }^{4} P_{5 / 2}-1 s 2 p{ }^{2} P_{3 / 2}$ transition with an oscillator strength of $2 \times 10^{-8}, 36 \%$ of the population within the $0.2 \mathrm{~mm}^{2}$ beam area could be transferred with about $10 \mathrm{~mJ}$ of laser energy.

The same apparatus was used to demonstrate anti-stokes scattering from the singlet and also triplet-singlet transfer in the $\mathrm{Li}^{+}$ion. Experimental results for the three cases are shown in Figs. 6, 7, and 8. It is of interest to note that, although the intercombination oscillator strength of the triplet transfer is about six orders of magnitude smaller than that for the singlet transfer, the laser still saturates the transition and the peak triplet transfer signal was only about five times smaller than that of the singlet transfer. The peak quartet signal was about $1 / 100$ times smaller than the singlet signal and the data of Fig. 8 required a total scanning time of about $2 \mathrm{~h}$.

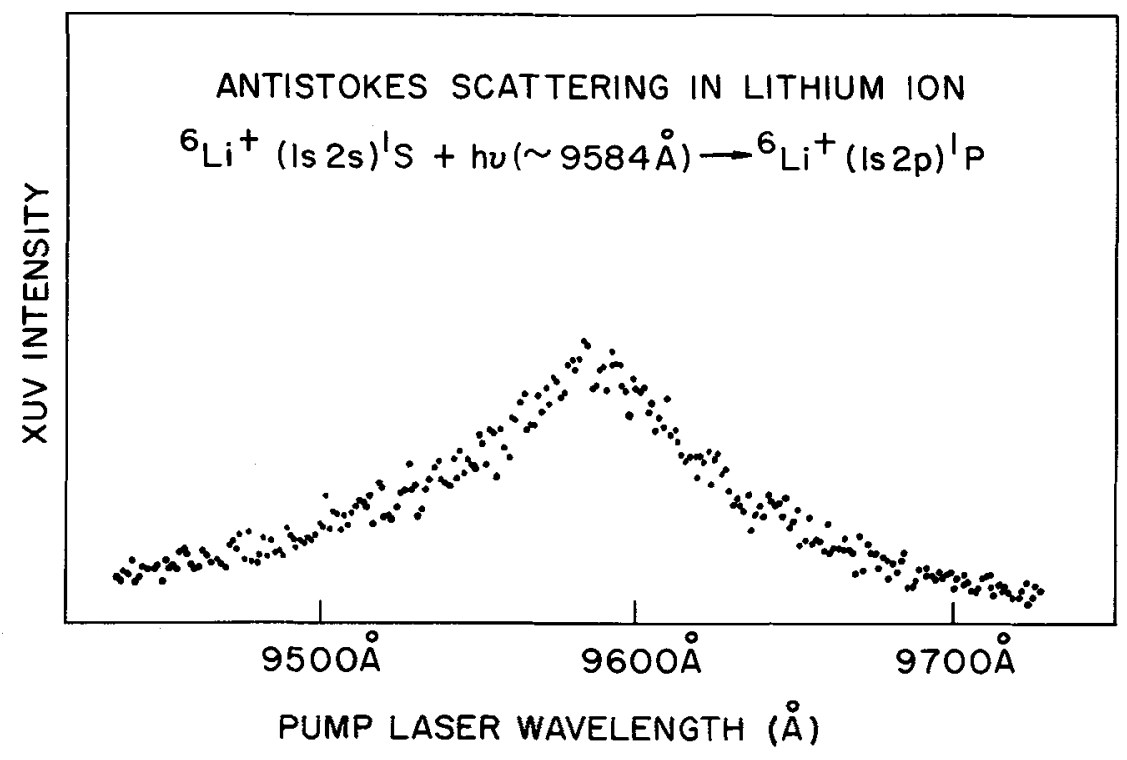

Fig. 6 : XUV intensity vs. laser wavelength for $1 s 2 s^{1} \mathrm{~S} \rightarrow 1 \mathrm{~s} 2 \mathrm{p}{ }^{1} \mathrm{P}$ transfer in ${ }^{6} \mathrm{Li}^{+}$. 

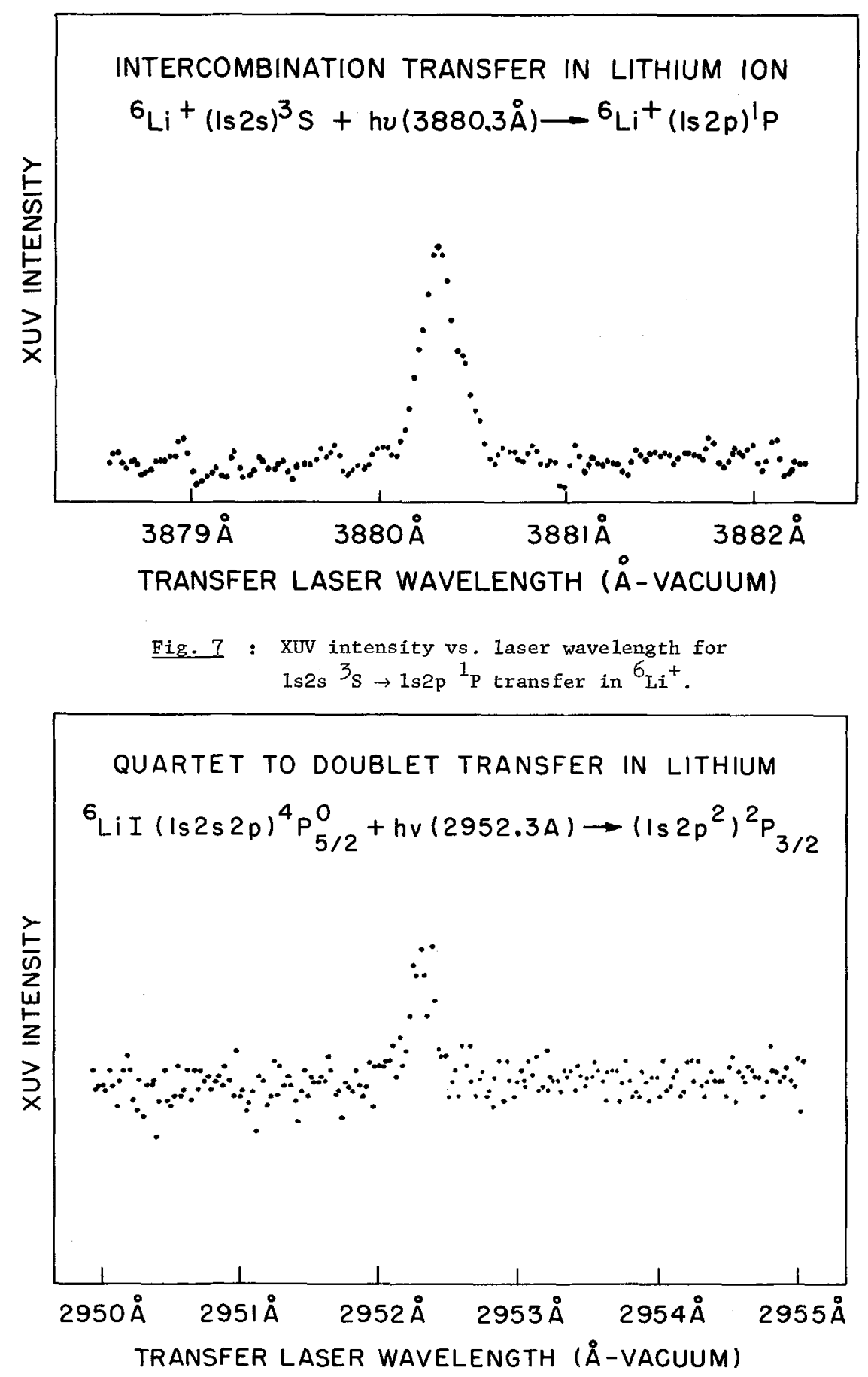

Fig. 8 : XUV intensity vs. 1aser wavelength for 1 s2s2p ${ }^{4} \mathrm{P}_{5 / 2} \rightarrow$ $1 \mathrm{~s} 2 \mathrm{p}^{2}{ }^{2} \mathrm{P}_{3 / 2}$ transfer in neutraI ${ }_{\mathrm{Li}^{+}}$. 
4. Two-Photon Pumping.- At this time, our most promising approach to the construction of a $200 \&$ laser is by means of two-photon pumping of the non-autoionizing $\left({ }^{2} \mathrm{P}\right.$ and $\left.{ }^{2} \mathrm{D}^{\circ}\right)$ levels of neutral Li. ${ }^{7}$ Energy level diagrams for anti-Stokes flashlamp pumping of the Li (1s2p) ${ }^{1} \mathrm{P}_{3 \mathrm{~d}^{2}} \mathrm{D}^{\circ}$ level are shown in Figs. 9 and 10 . In Fig. 9 the flashlamp is fired by a $9536 \AA$ laser (second stokes in $\mathrm{H}_{2}$ of $5320 \AA$ ) and the absorption of the generated photons is caused by a $6537 \AA$ 1aser. In Fig. 10 the flashlamp is fired by a $1.06 \mu \mathrm{m}$ laser and the two-photon absorption is caused by a near resonant $6104 \AA$ laser. In both cases the initial level $\left(1 s^{2} 2 p{ }^{2} p^{o}\right.$ ) is populated by the discharge and the terminal level $\left(1 s^{2} 3 d^{2} D\right)$ is assumed to be emptied by an additional laser in the wavelength window $8194 \AA-7554 \AA$, which ionizes the lower but not the upper laser leve1.

In first experiments we expect to study these processes by measuring the gain on the $2846 \AA$ transition (Fig. 10) within the upper manifold. Based on the measured $\mathrm{Li}^{+}$(1s2s) ${ }^{1} \mathrm{~S}$ population, and calculated oscillator strengths, we expect a gain of about $20 \%$ per $\mathrm{cm}$ on the $2846 \AA$ transition. The calculated gain, at present1y measured populations, on the $(1 \mathrm{~s} 2 \mathrm{p}){ }^{1} \mathrm{P} 3 \mathrm{~d}^{2} \mathrm{D}^{\circ}-1 \mathrm{~s}^{2} 3 \mathrm{~d}^{2} \mathrm{D}$ transition at $199.7 \&$ is about $1 \%$ per $\mathrm{cm}$.

$$
\mathrm{Li}^{+}
$$

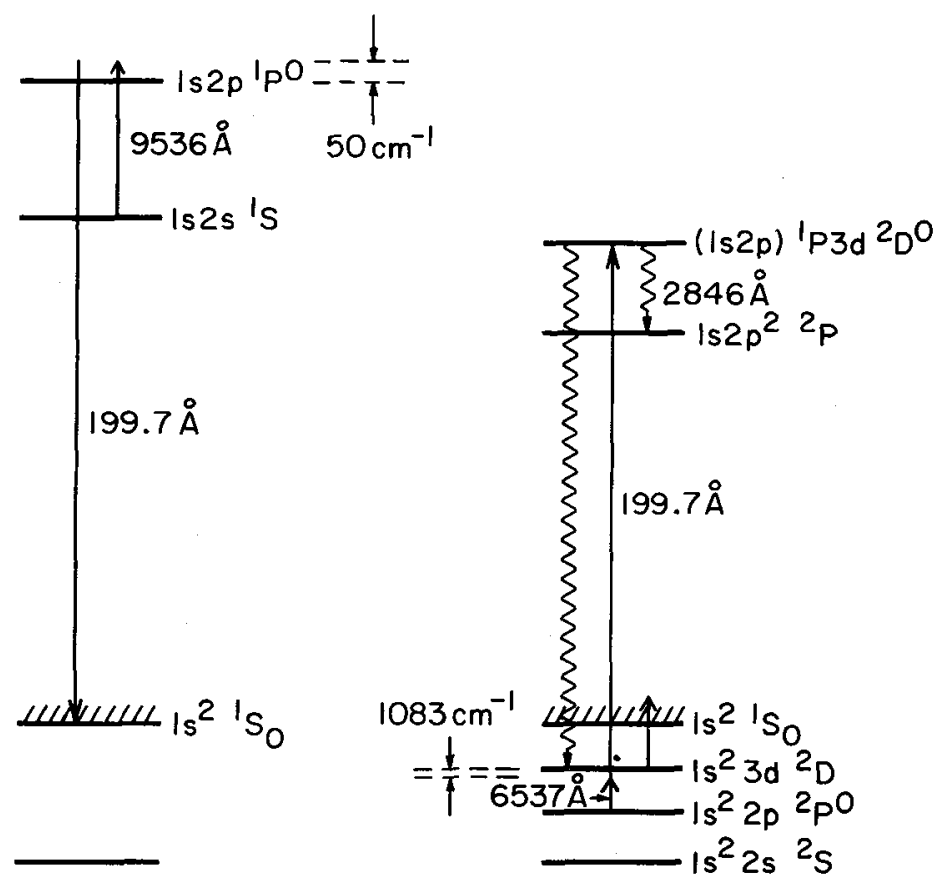

Fig. 9 : Twomphoton pumping of neutral $\mathrm{L} i$ using a near resonant anti-Stokes flashlamp. 


\section{$\mathrm{Li}^{+}$}

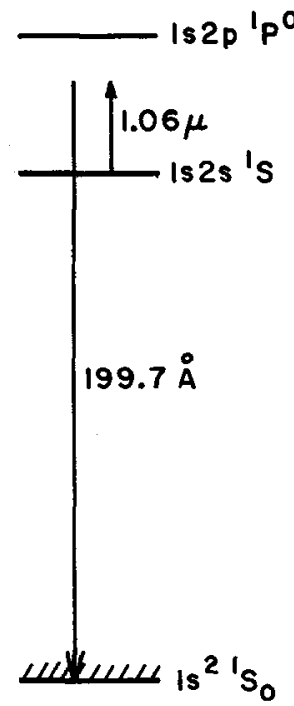

\section{$\mathrm{Li}$}

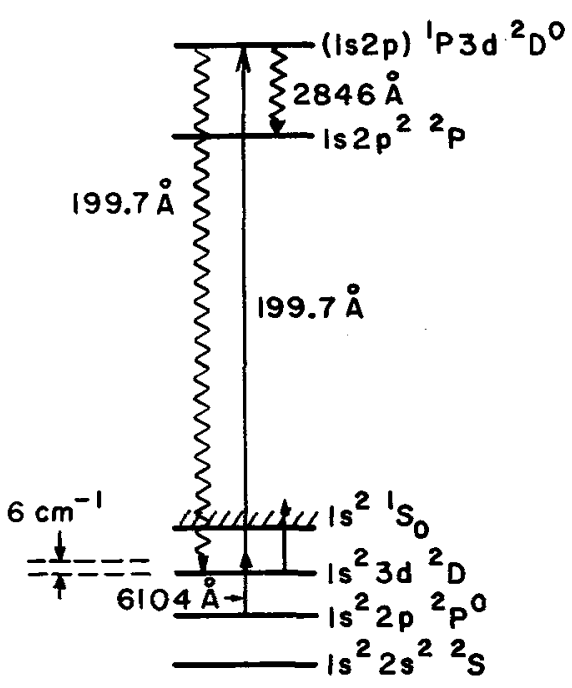

$\underline{\text { Fig. } 10}: 1.06 \mu \mathrm{m}$ flashlamp pumping of neutra1 Li.

5. Laser Designation.- Another approach to the spectroscopy of core-excited levels, and also possibly to the construction of a $200 \AA$ laser, is termed as laser designation. 7 In this case, one tunes a laser to the $1 s^{2} 3 \mathrm{~d}^{2} \mathrm{D}$ leve1, thereby "designating" the orbit of the outer electron. Hot electrons then cause $1 \mathrm{~s}-2 \mathrm{p}$ core excitation to populate the $(1 \mathrm{~s} 2 \mathrm{p}){ }^{1} \mathrm{P} 3 \mathrm{~d}^{2} \mathrm{D}^{\circ}$ leve1. We estimate a trapping time and, therefore, an allowable excitation time, of several ns. Following this excitation a second laser is used to rapidly ionize the (1s2p) ${ }^{1} \mathrm{P} 3 \mathrm{~d}^{2} \mathrm{D}^{\circ}$ leve1, allowing lasing at $199.7 \AA$.

Using laser designation we have observed fluorescence on the transition $(1 \mathrm{~s} 2 \mathrm{p}){ }^{1} \mathrm{P} 3 \mathrm{~d}^{2} \mathrm{D}^{\circ} \rightarrow 1 \mathrm{~s} 2 \mathrm{p}{ }^{2} \mathrm{P}$ at $2846 \AA$.

6. Excitation Technology.- Our work to date has emphasized pulsed hollow cathode technology which has been developed by Falcone and coworkers. ${ }^{8,9}$ A schematic of a "Tee"-type device is shown in Fig. 11. A $2.54 \mathrm{~cm}$ diameter stainless steel tube contains $L i$ and acts as an anode. The tee-shaped cathode is suspended by a conducting support rod, through which the negative voltage pulse is applied. The device operates at about $3 \mathrm{kv}$, draws a current of about 1000 amps, and has a pulse length of about $200 \mathrm{~ns}$. Table 2 gives the population densities which are measured 

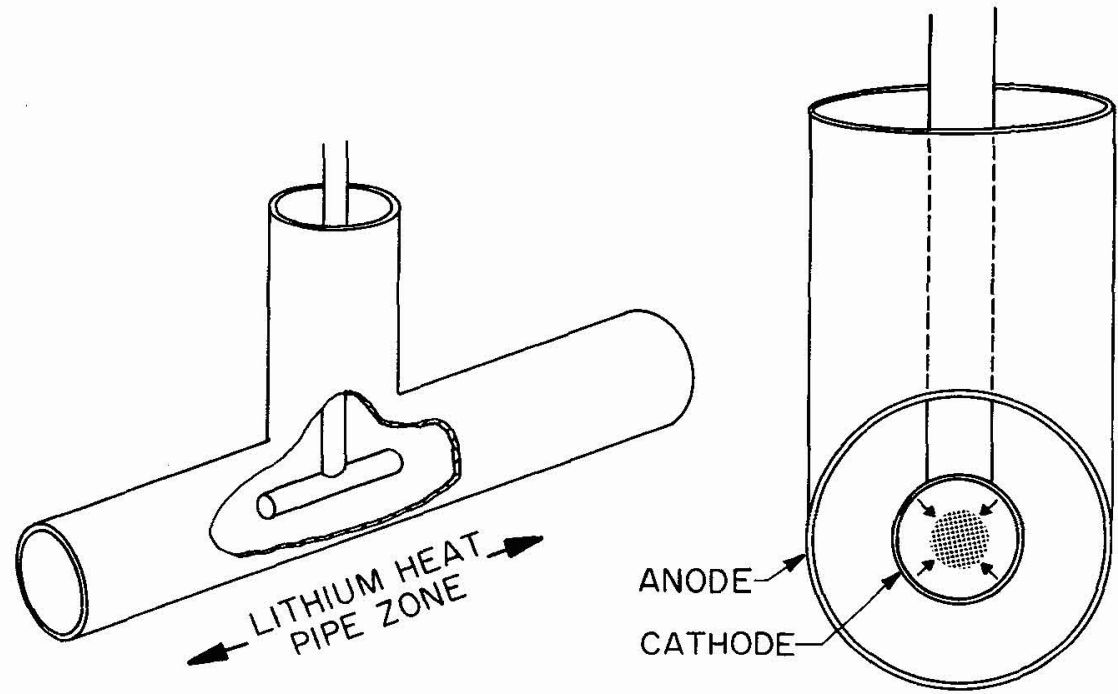

END VIEW

Fig. 11 : Diagram of the "tee"-type hollow-cathode discharge.

Table 2 : Lithium population densities measured in hollow-cathode discharge of Fig. 11.

\begin{tabular}{|l|c|c|}
\hline Species & $\begin{array}{c}\text { Number Density } \\
\left.\text { atoms } / \mathrm{cm}^{3}\right)\end{array}$ & $\begin{array}{c}\text { Energy Above } \\
\text { Ground State }\end{array}$ \\
\hline $\mathrm{Li}\left(1 \mathrm{~s}^{2} 2 \mathrm{~s}\right)$ & $9 \times 10^{16}$ &.- \\
$\mathrm{Li}\left(1 \mathrm{~s}^{2} 2 \mathrm{p}\right)$ & $4 \times 10^{16}$ & 1.8 \\
$\mathrm{Li}\left(1 \mathrm{~s}^{2} 3 \mathrm{~d}\right)$ & $1 \times 10^{13}$ & 3.9 \\
$\mathrm{Li}^{+}\left(1 \mathrm{~s}^{2}\right)$ & $4 \times 10^{14}$ & 5.4 \\
$\mathrm{Li}^{+}\left(1 \mathrm{~s} 2 \mathrm{~s}^{3} \mathrm{~S}\right)$ & $\approx 1 \times 10^{13}$ & $59.0^{*}$ \\
$\mathrm{Li}^{+}\left(1 \mathrm{~s} 2 \mathrm{~s}_{\mathrm{S}}\right)$ & $1.5 \times 10^{12}$ & $60.9^{*}$ \\
\hline
\end{tabular}

* Energy above ion ground state. 
in a $1.5 \mathrm{~cm}$ long cathode with a diameter of $5 \mathrm{~mm}$. These measurements were made with the curve of growth technique, except for the Ii ion ground level density which was obtained by measuring the stark broadening of the He II $3203 \AA$ ine. Note that population of about $10^{12}$ ions $/ \mathrm{cm}^{3}$ are produced in the singlet metastable level. Also, of potential importance for other applications such as radiative collision lasers, the stored energy in the $\mathrm{Li}$ resonance line is about 0.01 $\mathrm{J} / \mathrm{cm}^{3}$. The low population in the terminal laser level $\mathrm{Li}\left(1 \mathrm{~s}^{2} 3 \mathrm{~d}\right)$ (Figs. 10 and 11 ), is also of interest and is difficult to explain.

Another possible method of excitation of the $\mathrm{Li}$ metastable ion and perhaps the $200 \AA$ laser is shown in Fig. 12.7 Here, an intense $1.06 \mathrm{~mm}$ 1aser is focused onto a tantalum target so as to produce a burst of incoherent, broadband XUV radiation with a temperature of perhaps $50 \mathrm{eV}$. This radiation would be absorbed by Li vapor with an absorption cross section of about $10^{-18} \mathrm{~cm}^{2}$ to produce $\mathrm{Li}^{+}$(1s2s) ${ }^{1} \mathrm{~S}$ ions, thereby integrating the broadband radiation over frequency and time. A picosecond pulse near $9584 \AA$ would then cause an intense burst of flashlamp radiation at $199 \AA$, which, as described earlier, would then be absorbed by the neutral Li target.

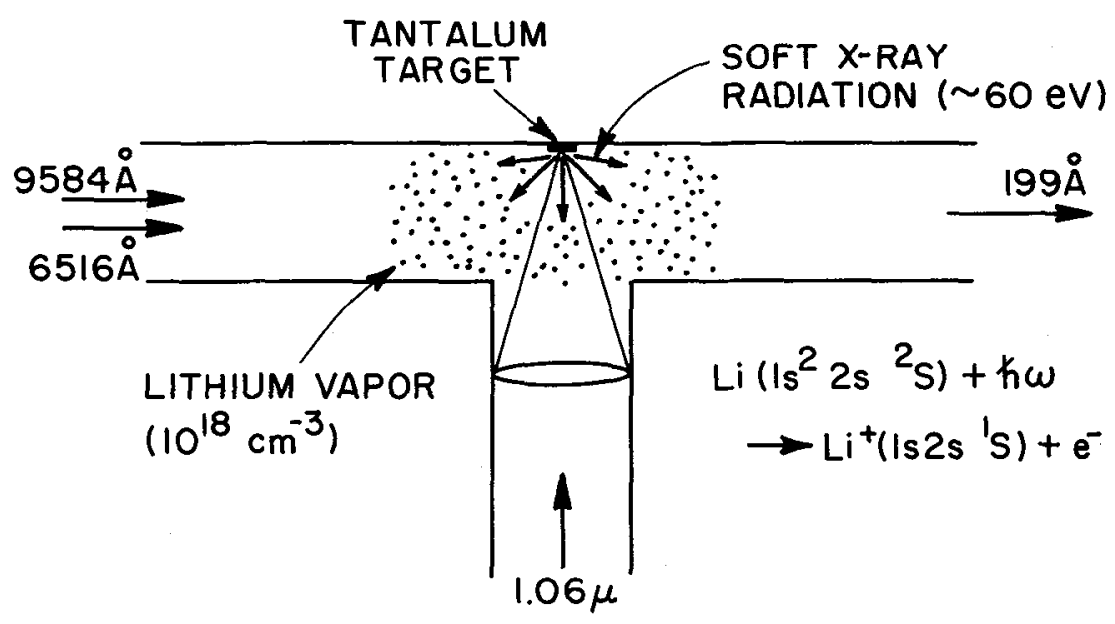

Fig. 12 : Soft $\mathrm{x}$-ray excitation of the $\mathrm{Li}^{+}$flashlamp.

7. Summary.- We have begun the study of a number of new techniques which use lasers to study the core-excited levels of atoms. These include anti-Stokes absorption spectroscopy, laser-induced emission spectroscopy, and laser designation. Each of these techniques is at a very early stage of development. For example, if the microwave excitation method used in the quartet to doublet experiment described above is replaced with the pulsed hollow-cathode discharge, a gain in signal strength of a factor of almost $10^{3}$ is expected. In the same spirit, large 
improvements in the signal to noise ratio of the anti-Stokes absorption technique may be obtainable by using picosecond laser sources and fast gated detectors.

8. Acknowledgements.- The authors gratefully acknowledge discussions with $R$. G. Caro, D. E. Holmgren, K. D. Pedrotti, and J. C. Wang. The work described here was supported by the Office of Naval Research, the Air Force Office of Scientific Research, the Army Research Office, and the Nationa1 Aeronautics and Space Administration.

\section{References}

1. S. E. Harris, "Proposa1 for a $207 \&$ Laser in Lithium," Optics Lett. 2, 1 (January 1980).

2. Joshua E. Rothenberg and S. E. Harris, 'XUV Lasers by Quartet to Doublet Energy Transfer in Alkali Atoms," IEEE J. Quant. Elect. QE-17, 418 (March 1981).

3. S. E. Harris, "Spontaneous Anti-Stokes Scattering as a High Resolution and Picosecond Time Scale VUV Light Source," App1. Phys. Lett. 21, 498 (October 1977 ).

4. L. J. Zych, J. Lukasik, J. F. Young, and S. E. Harris, "Laser Induced TwoPhoton Blackbody Radiation in the VUV," Phys. Rev. Lett. 40, 1493 (June 1978 ).

5. Joshua E. Rothenberg, J. F. Young, and S. E. Harris, "High Resolution XUV Spectroscopy of Potassium Using Anti-Stokes Radiation," Optics Lett. 6 , 363 (August 1981).

6. J. R. Willison, R. W. Falcone, J. F. Young, and S. E. Harris, "Laser Spectroscopy of Metastable XUV Levels in Lithium Atoms and Ions," Phys. Rev. Lett. 47, 1827 (December 1981).

7. S. E. Harris, J. F. Young, R. W. Falcone, Joshua E. Rothenberg, J. R. Willison, and J. C. Wang, "Anti-Stokes Scattering as an XUV Radiation Source and Flashlamp," in Laser Techniques for Extreme U1traviolet Spectroscopy, R. R. Freeman and T. J. McIlrath, eds. (New York: AIP, 1982) (to be published).

8. R. W. Falcone and K. D. Pedrotti, "Pulsed Hollow Cathode Discharge for XUV Lasers and Radiation Sources," Optics Lett. 7, 74 (February 1982).

9. R. W. Falcone, D. E. Holmgren, and K. D. Pedrotti, "Hollow-Cathode Discharge for XUV Lasers and Radiation Sources," in Laser Techniques for Extreme U1traviolet Spectroscopy, R. R. Freeman and T. J. McIlrath, eds. (New York: AIP, 1982) (to be published). 